\title{
Association Between Waiting Time from Diagnosis to Treatment and Survival in Patients with Curable Gastric Cancer: A Population-Based Study in the Netherlands
}

\author{
H. J. F. Brenkman, MD ${ }^{1}$ (D) E. Visser, MD ${ }^{1}$, P. S. N. van Rossum, MD, PhD ${ }^{1,2}$, S. Siesling, MD, $\mathrm{PhD}^{3,4}$, \\ R. van Hillegersberg, $\mathrm{MD}, \mathbf{P h D}^{\mathbf{1}}$, and J. P. Ruurda, $\mathbf{M D}, \mathbf{P h D}^{\mathbf{1}}$ \\ ${ }^{1}$ Department of Surgery, University Medical Center Utrecht, Utrecht, The Netherlands; ${ }^{2}$ Department of Radiation \\ Oncology, University Medical Center Utrecht, Utrecht, The Netherlands; ${ }^{3}$ Department of Research, Netherlands \\ Comprehensive Cancer Organisation, Utrecht, The Netherlands; ${ }^{4}$ Department of Health Technology and Services \\ Research, MIRA Institute for Biomedical Technology and Technical Medicine, University of Twente, Enschede, \\ The Netherlands
}

\begin{abstract}
Background. In the Netherlands, a maximum waiting time from diagnosis to treatment (WT) of 5 weeks is recommended for curative cancer treatment. This study aimed to evaluate the association between WT and overall survival (OS) in patients undergoing gastrectomy for cancer. Methods. This nationwide study included data from patients diagnosed with curable gastric adenocarcinoma between 2005 and 2014 from the Netherlands Cancer Registry. Patients were divided into two groups: patients who received neoadjuvant therapy followed by gastrectomy, or patients who underwent gastrectomy as primary surgery. WT was analyzed as a categorical ( $\leq 5$ weeks [Reference], 5-8 weeks, >8 weeks) and as a discrete variable. Multivariable Cox regression analysis was used to assess the influence of WT on OS.

Results. Among 3778 patients, 1701 received neoadjuvant chemotherapy followed by gastrectomy, and 2077 underwent primary gastrectomy. In the neoadjuvant group, median WT to neoadjuvant treatment was 4.6 weeks (interquartile range [IQR] 3.4-6.0), and median OS was
\end{abstract}

H. J. F. Brenkman, E. Visser have contributed equally to this manuscript.

(C) The Author(s) 2017. This article is an open access publication

First Received: 6 December 2016;

Published Online: 28 March 2017

J. P. Ruurda, MD, PhD

e-mail: J.P.Ruurda@umcutrecht.nl
32 months. In the surgery group, median WT to surgery was 6.0 weeks (IQR 4.3-8.4), and median OS was 25 months. For both groups, WT did not influence OS (neoadjuvant: 5-8 weeks, hazard ratio [HR] 0.82, $p=0.068 ;>8$ weeks, HR $0.85, p=0.354$; each additional week WT, HR 0.96, $p=0.078$; surgery: $5-8$ weeks, HR $0.91, p=0.175$; $>8$ weeks, HR $0.92, p=0.314$; each additional week WT, HR $0.99, p=0.264$ ).

Conclusions. Longer WT until the start of curative treatment for gastric cancer is not associated with worse OS. These results could help to put WT into perspective as indicator of quality of care and reassure patients with gastric cancer.

Gastric cancer is the fifth most common type of cancer worldwide. ${ }^{1}$ In the Netherlands, only a third of patients with gastric cancer qualify for curative treatment, which consists of surgical resection with D2 lymphadenectomy with or without perioperative chemotherapy.,3 Unfortunately, the 5-year overall survival (OS) after curative treatment remains poor $(35-45 \%){ }^{3-5}$

The interval from diagnosis to treatment (waiting time, WT) is considered to be an important quality indicator for cancer care because it negatively influences patients' quality of life, results in psychologic distress, and has been demonstrated to be associated with oncologic outcomes in various cancers. ${ }^{6-8}$ Hence, in the Netherlands, WT to the start of curative treatment for gastric cancer is an important quality indicator as recommended by the Dutch Hospitals Association, the Dutch Federation of University Medical Centres, the Ministry of Health, Welfare and Sport, and the 
Association of Surgical Oncologists. ${ }^{6,9,10}$ However, the biology and behavior of tumors vary, indicating that the impact of WT for each type of cancer may differ. Therefore, there is a need for cancer-specific recommendations.

Only one study has reported on this topic for gastric cancer specifically. ${ }^{11}$ This study was performed in the Asian population, which differs significantly from the Western population and generally does not undergo neoadjuvant treatment. ${ }^{11,12}$ The aim of the current study was to evaluate the association between WT and OS in a large Western population-based cohort of patients undergoing curative gastrectomy with or without perioperative chemotherapy for cancer. It was hypothesized that longer WTs are associated with worse OS as a result of disease progression.

\section{MATERIALS AND METHODS}

\section{Study Design}

This population-based cohort study was conducted with data from the Netherlands Cancer Registry (NCR). In the Netherlands, a population of 17 million inhabitants, all newly diagnosed cancers are registered in the NCR, which is hosted by the Netherlands Comprehensive Cancer Organisation (IKNL). The main source of notification is the National Automated Pathology Archive, which sends weekly notifications of all cancer cases. Furthermore, yearly, the National Registry of Hospital Discharge Diagnoses is linked to the NCR to obtain clinical cancer diagnosis only. On a daily basis, trained data managers register data from hospital records within all Dutch hospitals using the NCR's registration and coding manual. The privacy committee of the NCR approved this study.

\section{Patient Population}

In this study, all patients diagnosed with curable gastric adenocarcinoma (cT1-4a, N0-3, M0) in the period 2005-2014 were selected from the NCR. Exclusion criteria consisted of neoadjuvant therapy other than chemotherapy and emergency gastrectomy (gastrectomy $\leq 14$ days after diagnosis or start of neoadjuvant treatment). Patients who were diagnosed with curable gastric cancer (cTNM) but who underwent a palliative resection (pTNM) were deliberately included in this study, as this might reflect disease progression during WT.

Disease was staged, and patients underwent treatment according to the nationwide guidelines for gastric cancer. ${ }^{2}$ Staging consisted of a gastroscopy and a computed tomographic scan in all patients, whereas endoscopic ultrasound and diagnostic laparoscopy were not routinely performed. Before 2006, the standard of treatment consisted of gastrectomy only, and after that, an increasing number of patients underwent perioperative chemotherapy. ${ }^{3}$ Surgery consisted of a distal or total gastrectomy, depending on the possibility to achieve an adequate proximal resection margin $(\geq 6 \mathrm{~cm})$, along with a D2 lymphadenectomy (without station 10 dissection and without pancreaticosplenectomy). ${ }^{13,14}$ The resected specimens were reviewed by pathologists and presented according to the American Joint Committee on Cancer tumor, node, metastasis classification system (TNM) staging system (7th edition).

\section{Statistical Analysis and Outcome Measures}

All included patients were divided into two groups: a neoadjuvant group and a surgery group. Patients in the neoadjuvant group received neoadjuvant chemotherapy (as part of perioperative chemotherapy) followed by gastrectomy, whereas patients in the surgery group underwent gastrectomy only. The WT was calculated in weeks and was defined as the interval between the date of diagnosis and the start date of neoadjuvant chemotherapy for the neoadjuvant group, and as the interval between the date of diagnosis and the date of gastrectomy for the surgery group. The date of diagnosis was used as the date of the first gastrointestinal endoscopy, on which the diagnosis of gastric cancer had been established by histology from biopsy samples. The WT constitutes a combination of time needed to confirm the diagnosis of gastric cancer, referral time, staging, pretherapeutic assessment, and actual WT for treatment. ${ }^{2}$ WT was grouped into three categories of $\leq 5$ weeks, $5-8$ weeks, and $>8$ weeks on the basis of national recommendations and previous studies. ${ }^{6,15,16}$ In both groups, a subgroup was made of patients who underwent a curative gastrectomy (pT1-4aN $+\mathrm{M} 0)$ and palliative gastrectomy (detected unresectable tumor [pT4b] and/or metastatic disease [M1] intraoperatively). Missing baseline data were considered at random and handled using multiple imputation with the iterative Markov chain Monte Carlo methods (20 iterations).

To assess the association between WT and tumor progression, the median WT was compared between the curative and palliative treated patients by the MannWhitney $U$ test. To assess the distribution of all baseline, surgical, and histopathologic characteristics in the different WT groups ( $\leq 5,5-8,>8$ weeks), all baseline, surgical, and histopathologic characteristics were compared among the three groups of WT. Categorical variables were analyzed by the Chi square test, and continuous variables were compared by the parametric ANOVA test.

To assess the association between WT and OS, univariable and multivariable analyses by means of Cox proportional hazard models were used, providing hazard ratios (HRs) with $95 \%$ confidence intervals. WT was 
analyzed as a categorical variable and as a discrete variable. All baseline variables and WT were entered in a multivariable analysis. Sensitivity analyses were performed for the following subgroups: cT1-2 versus cT3-4, good to moderate versus poor to undifferentiated tumors, and $\mathrm{cN} 0$ versus $\mathrm{cN}+$. OS was defined as the time from the start date of treatment to the date of death from any cause or to the date of last follow-up (December 2015). A $p$ value of $<0.05$ was considered statistically significant. All statistical analyses were performed by IBM SPSS 21 for Windows.

\section{RESULTS}

\section{Study Population}

The NCR selected data from 4088 patients diagnosed with curable gastric adenocarcinoma (2005-2014). A total of 310 patients were excluded because of neoadjuvant therapy other than chemotherapy $(n=30)$ and emergency gastrectomy $(n=280)$. Of the remaining 3778 patients, 1701 received neoadjuvant chemotherapy followed by gastrectomy, and the other 2077 patients underwent primary gastrectomy.

Baseline characteristics of the neoadjuvant group are presented in Table 1. The mean age was 62.6 years, most of the patients were male $(n=1064,63 \%)$, and most were clinically staged as having cT1-2 $(n=483,55 \%)$ and cN0 $(n=951,65 \%)$ disease. The majority underwent a distal gastrectomy $(n=924,54 \%)$ and an open surgical approach $(n=1447,86 \%)$. A curative gastrectomy was performed in 1544 patients $(92 \%)$. The other 127 patients $(8 \%)$ received a palliative resection (pT4b or pM1 intraoperatively).

Baseline characteristics of the surgery group data are presented in Table 2. The mean age was 73.5 years, most of the patients were male $(n=1253,60 \%)$, and most were clinically staged as having cT1-2 $(n=486,67 \%)$ and $\mathrm{cN} 0$ $(n=1326,77 \%)$ disease. The majority underwent a distal gastrectomy $(n=1435,69 \%)$ and an open approach $(n=1908,94 \%)$. A curative gastrectomy was performed in 1946 patients (94\%), and a palliative resection (pT4b or pM1 intraoperatively) was performed in 120 patients (6\%).

\section{WT and Related Variables}

The WT to neoadjuvant therapy was missing in 215 patients (13\%), the result of an unknown start date for neoadjuvant treatment. Median WT was 4.6 weeks (interquartile range [IQR] 3.4-6.0). The median WT did not significantly differ between the curative (pT1-4a, N0-3, $\mathrm{M} 0$ ) and palliative (pT4b and/or pM1) treated patients (4.6 vs. 4.1 weeks, $p=0.136$ ). The groups of $\leq 5$ weeks,
5-8 weeks, and $>8$ weeks consisted of 895 (60\%), 451 (30\%), and 140 (9\%) patients, respectively (Table 1). The only difference with regard to baseline characteristics included referral status $(p<0.001)$. Surgical and histopathologic characteristics differed on ypT stage $(p<0.001)$, ypN stage $(p=0.036)$, and adjuvant therapy $(p=0.009)$. Patients with pathologic advanced tumor stages had significantly shorter WTs compared to patients with early tumor stages.

In the surgery group, the WT was available in all 2077 patients. Median WT was 6.0 weeks (IQR 4.3-8.4). The median WT was significantly longer in the curative-treated patients compared to the palliative-treated patients $(6.1 \mathrm{vs}$. 5.1 weeks, $p=0.005)$. The groups of $\leq 5$ weeks, 5-8 weeks, and $>8$ weeks consisted of 772 (37\%), 727 (35\%), and 578 (28\%) patients, respectively (Table 2). Age $(p<0.001)$, tumor differentiation $(p=0.008)$, cT stage $(p<0.001)$, cN stage $(p<0.001)$, year of diagnosis $(p<0.001)$, and referral status $(p<0.001)$ all significantly differed between the groups. Most importantly, patients with clinical advanced tumor stages had a significantly shorter WT to gastrectomy compared to patients with early tumor stages. Furthermore, WT increased over the years both in the categorized WT groups (Table 2) as in median WT (2006-2008: 5.4 weeks; 2009-2011: 6.6 weeks; 2012-2014: 6.7 weeks). Regarding surgical and histopathologic characteristics, surgical type $(p=0.008)$, surgical approach $(p=0.002)$, radicality $(p=0.003)$, pT stage $(p<0.001)$, pN stage $(p<0.001)$, curative intent $(p=0.035)$, and adjuvant therapy $(p=0.043)$ differed significantly between the WT groups. Patients who underwent an irradical resection or a resection for pathologic advanced tumor stages had significantly shorter WTs.

\section{Overall Survival}

Median OS in the neoadjuvant group was 32 months (range 1-118 months), and 1-, 3-, and 5-year survival rates were 86,58 , and $47 \%$, respectively. The categorized and linear effect of WT on OS is presented in Table 3. In multivariable analysis, both the categorized and the discrete variables of WT were not identified as independent prognostic factors associated with OS (WT 5-8 weeks vs. $\leq 5$ weeks, HR $0.82, p=0.68 ;>8$ weeks vs. $\leq 5$ weeks, HR $0.85, p=0.354$; and additional week WT, HR 0.96, $p=0.065)$.

Median OS in the surgery group was 25 months (range 0-120 months), and 1-, 3-, and 5-year survival rates were 73,46 , and $37 \%$, respectively. The categorized and linear effect of WT on OS is presented in Table 3. In multivariable analyses, both the categorized and discrete variables of WT were not identified as independent prognostic factors associated with OS (WT 5-8 weeks vs. $\leq 5$ weeks, HR 
TABLE 1 Baseline, surgical, and histopathologic characteristics of 1701 patients treated with neoadjuvant chemotherapy followed by gastrectomy for cancer

\begin{tabular}{|c|c|c|c|c|c|c|c|c|c|}
\hline \multirow[t]{2}{*}{ Characteristic } & \multicolumn{2}{|c|}{ All $(N=1701)$} & \multicolumn{2}{|c|}{$<5$ weeks $(n=895)$} & \multicolumn{2}{|c|}{$5-8$ weeks $(n=451)$} & \multicolumn{2}{|c|}{$>8$ weeks $(n=140)$} & \multirow[t]{2}{*}{$p$} \\
\hline & $n$ & $\%$ & $n$ & $(\%)$ & $n$ & $(\%)$ & $n$ & $(\%)$ & \\
\hline \multicolumn{10}{|l|}{ Baseline characteristics } \\
\hline Age, year, mean $( \pm S D)$ & 62.6 & $( \pm 10.6)$ & 62.4 & $(10.7)$ & 63.2 & $(10.5)$ & 62.4 & $(9.0)$ & 0.386 \\
\hline Gender & & & & & & & & & 0.479 \\
\hline Male & 1064 & $(63)$ & 548 & $(59)$ & 287 & $(31)$ & 92 & (10) & \\
\hline Female & 637 & (37) & 347 & $(62)$ & 164 & (29) & 48 & (9) & \\
\hline Malignancy history & & & & & & & & & 0.934 \\
\hline No & 1546 & $(91)$ & 814 & $(60)$ & 409 & $(30)$ & 126 & (9) & \\
\hline Yes & 155 & (9) & 81 & $(59)$ & 42 & $(31)$ & 14 & $(10)$ & \\
\hline Tumor differentiation & & & & & & & & & 0.163 \\
\hline Good to moderate & 202 & $(20)$ & 110 & $(21)$ & 44 & (17) & 19 & $(26)$ & \\
\hline Poor to undifferentiated & 798 & $(80)$ & 403 & (79) & 217 & $(83)$ & 55 & (74) & \\
\hline Missing & 701 & & 382 & & 190 & & 66 & & \\
\hline cT stage & & & & & & & & & 0.399 \\
\hline $\mathrm{T} 1$ & 44 & (5) & 22 & $(55)$ & 12 & $(30)$ & 6 & $(15)$ & \\
\hline $\mathrm{T} 2$ & 439 & $(50)$ & 235 & $(56)$ & 138 & (33) & 45 & (11) & \\
\hline $\mathrm{T} 3$ & 304 & (35) & 158 & $(55)$ & 97 & (34) & 30 & (11) & \\
\hline $\mathrm{T} 4 \mathrm{a}$ & 88 & $(10)$ & 33 & $(45)$ & 26 & (36) & 14 & (19) & \\
\hline $\mathrm{Tx}$ & 826 & & 447 & & 178 & & 45 & & \\
\hline cN stage & & & & & & & & & 0.466 \\
\hline No & 951 & $(65)$ & 504 & $(58)$ & 277 & $(32)$ & 82 & (10) & \\
\hline $\mathrm{N}+$ & 511 & (35) & 285 & $(62)$ & 134 & $(29)$ & 42 & (9) & \\
\hline $\mathrm{Nx}$ & 239 & & 106 & & 40 & & 16 & & \\
\hline Year of diagnosis & & & & & & & & & 0.268 \\
\hline 2006-2008 & 356 & (21) & 120 & $(59)$ & 57 & (28) & 28 & (14) & \\
\hline 2009-2011 & 616 & $(36)$ & 339 & (61) & 170 & $(30)$ & 49 & (9) & \\
\hline 2012-2014 & 729 & $(43)$ & 436 & $(60)$ & 224 & $(31)$ & 63 & (9) & \\
\hline Referral status & & & & & & & & & $<0.001$ \\
\hline Diagnosis in treatment hospital & 1009 & $(69)$ & 536 & $(53)$ & 233 & $(23)$ & 64 & (6) & \\
\hline Diagnosis in other hospital & 445 & $(31)$ & 211 & $(47)$ & 144 & $(32)$ & 53 & $(12)$ & \\
\hline Missing & 247 & & 148 & & 74 & & 23 & & \\
\hline \multicolumn{10}{|c|}{ Treatment and histopathologic characteristics } \\
\hline Surgical type & & & & & & & & & 0.687 \\
\hline Distal gastrectomy & 924 & $(54)$ & 487 & $(61)$ & 236 & $(30)$ & 77 & (10) & \\
\hline Total gastrectomy & 749 & (44) & 394 & (59) & 211 & $(32)$ & 62 & (9) & \\
\hline Multiorgan surgery & 28 & (2) & 14 & (74) & 4 & $(21)$ & 1 & (5) & \\
\hline Surgical approach & & & & & & & & & 0.679 \\
\hline Open & 1447 & $(86)$ & 742 & $(60)$ & 373 & (30) & 119 & (10) & \\
\hline Laparoscopic & 230 & (14) & 141 & $(62)$ & 69 & (30) & 18 & (8) & \\
\hline Missing & 24 & & 12 & & 9 & & 3 & & \\
\hline Radicality & & & & & & & & & 0.782 \\
\hline R0 & 1405 & (86) & 738 & $(60)$ & 368 & $(30)$ & 116 & (9) & \\
\hline $\mathrm{R} 1-2$ & 239 & $(15)$ & 129 & (61) & 66 & $(31)$ & 17 & (8) & \\
\hline Missing & 57 & & 28 & & 17 & & 7 & & \\
\hline ypT stage & & & & & & & & & $<0.001$ \\
\hline T0 & 112 & (7) & 56 & (57) & 37 & (37) & 6 & (6) & \\
\hline $\mathrm{T} 1$ & 236 & (14) & 96 & (48) & 69 & (34) & 36 & (18) & \\
\hline
\end{tabular}


TABLE 1 continued

\begin{tabular}{|c|c|c|c|c|c|c|c|c|c|}
\hline \multirow[t]{2}{*}{ Characteristic } & \multicolumn{2}{|c|}{ All $(N=1701)$} & \multicolumn{2}{|c|}{$<5$ weeks $(n=895)$} & \multicolumn{2}{|c|}{$5-8$ weeks $(n=451)$} & \multicolumn{2}{|c|}{$>8$ weeks $(n=140)$} & \multirow[t]{2}{*}{$p$} \\
\hline & $n$ & $\%$ & $n$ & $(\%)$ & $n$ & $(\%)$ & $n$ & $(\%)$ & \\
\hline $\mathrm{T} 2$ & 256 & $(15)$ & 142 & $(62)$ & 67 & (29) & 20 & (9) & \\
\hline $\mathrm{T} 3$ & 700 & $(42)$ & 385 & (62) & 186 & $(30)$ & 48 & (8) & \\
\hline $\mathrm{T} 4 \mathrm{a}$ & 309 & (19) & 162 & $(62)$ & 73 & (28) & 25 & $(10)$ & \\
\hline $\mathrm{T} 4 \mathrm{~b}$ & 57 & (3) & 39 & (74) & 11 & $(21)$ & 3 & (6) & \\
\hline $\mathrm{Tx}$ & 31 & & 15 & & 8 & & 2 & & \\
\hline ypN stage & & & & & & & & & 0.036 \\
\hline N0 & 805 & (47) & 387 & $(55)$ & 234 & (33) & 80 & $(11)$ & \\
\hline N1 & 338 & $(20)$ & 193 & (67) & 78 & (27) & 19 & (7) & \\
\hline $\mathrm{N} 2$ & 274 & $(16)$ & 147 & $(63)$ & 64 & (28) & 21 & (9) & \\
\hline N3 & 282 & (17) & 168 & (64) & 75 & (29) & 20 & (8) & \\
\hline $\mathrm{Nx}$ & 2 & & & & & & & & \\
\hline ypM stage & & & & & & & & & 0.357 \\
\hline M0 & 1625 & (96) & 885 & (61) & 438 & (30) & 135 & (9) & \\
\hline M1 & 76 & (5) & 40 & (69) & 13 & (22) & 5 & (9) & \\
\hline Curative intent & & & & & & & & & 0.112 \\
\hline Yes & 1544 & $(92)$ & 807 & (57) & 419 & (30) & 188 & (13) & \\
\hline No & 127 & (8) & 74 & (62) & 24 & (20) & 21 & (18) & \\
\hline Missing & 30 & & 14 & & 8 & & 6 & & \\
\hline 90-day mortality & 69 & (4) & 40 & (4) & 12 & (3) & 7 & (5) & 0.223 \\
\hline Adjuvant therapy & & & & & & & & & 0.009 \\
\hline No & 724 & (43) & 371 & (59) & 200 & (32) & 62 & (10) & \\
\hline Chemotherapy & 783 & (46) & 429 & (64) & 185 & (27) & 61 & (9) & \\
\hline Radiotherapy & 5 & $(<1)$ & 2 & $(50)$ & 0 & $(0)$ & 2 & $(50)$ & \\
\hline Chemoradiation & 189 & (11) & 93 & (53) & 66 & (38) & 15 & (9) & \\
\hline
\end{tabular}

0.91, $p=0.175 ;>8$ weeks vs. $\leq 5$ weeks, HR 0.92, $p=0.314$; and additional week WT, HR 0.99, $p=0.264$ ). Sensitivity analyses did not significantly change the HR estimates of the original multivariable analyses.

\section{DISCUSSION}

This population-based cohort study examined whether WT between diagnosis and start of treatment with curative intent was associated with OS in patients with gastric cancer. The results demonstrated that WT was not associated with OS in either patients treated with neoadjuvant chemotherapy or primary gastrectomy. The study is novel in that it is the first to be conducted in the West and the first to evaluate the association of WT between diagnosis and the start of neoadjuvant therapy, which has become the standard of care.

This study was conducted with the hypothesis that longer WTs might lead to a worse OS through disease progression, as has been shown for breast cancer, uterine cancer, and head and neck cancer. ${ }^{17-19}$ For lung cancer, pancreatic head cancer, colorectal cancer, and esophageal cancer, however, studies could not demonstrate this relationship. ${ }^{8,14,20-22}$ For gastric cancer specifically, a previous study reported that a longer WT did not adversely affect survival. ${ }^{11}$ Unfortunately, this study did not investigate the WT between diagnosis and the start of neoadjuvant treatment, and it was conducted in an Asian population, which differs significantly from a Western population. ${ }^{12}$ The results of the present study are therefore reassuring and confirm that WT does not adversely affect survival. The varying impact of WT for different cancer types may be explained by differences in duration of patient delay and diagnostic delay. The variety of these delays between cancer types may be related to the cancer site, time of manifestation of symptoms, and presence or absence of screening programs. Compared to these delays (months to years), WT from diagnosis to treatment (weeks to months) is relatively short and may have a negligible effect on OS, as this study demonstrated for gastric cancer. ${ }^{23}$

Interestingly, this study found that in both groups, patients with pathologic advanced tumor stages had shorter 
TABLE 2 Baseline, surgical and histopathologic characteristics of 2077 patients treated with primary gastrectomy for cancer

\begin{tabular}{|c|c|c|c|c|c|c|c|c|c|}
\hline \multirow[t]{2}{*}{ Characteristic } & \multicolumn{2}{|c|}{ All $(N=2077)$} & \multicolumn{2}{|c|}{$<5$ weeks $(n=772)$} & \multicolumn{2}{|c|}{$5-8$ weeks $(n=727)$} & \multicolumn{2}{|c|}{$>8$ weeks $(n=578)$} & \multirow[t]{2}{*}{$p$} \\
\hline & $n$ & $(\%)$ & $n$ & $(\%)$ & $n$ & $(\%)$ & $n$ & $(\%)$ & \\
\hline \multicolumn{10}{|l|}{ Baseline characteristics } \\
\hline Age, year, mean $( \pm S D)$ & 73.5 & $( \pm 10.1)$ & 73.2 & $(10.4)$ & 74.6 & $(8.9)$ & 72.3 & $(11.1)$ & $<0.001$ \\
\hline Gender & & & & & & & & & 0.345 \\
\hline Male & 1253 & $(60)$ & 461 & $(37)$ & 429 & (34) & 363 & $(29)$ & \\
\hline Female & 824 & $(40)$ & 311 & (38) & 298 & $(36)$ & 215 & (26) & \\
\hline Malignancy history & & & & & & & & & 0.393 \\
\hline No & 1745 & (84) & 659 & $(38)$ & 608 & $(35)$ & 478 & (27) & \\
\hline Yes & 332 & (16) & 113 & (34) & 119 & (36) & 100 & $(30)$ & \\
\hline Tumor differentiation & & & & & & & & & 0.008 \\
\hline Good to moderate & 582 & (34) & 212 & $(31)$ & 197 & (33) & 173 & $(40)$ & \\
\hline Poor to undifferentiated & 1131 & $(66)$ & 467 & (69) & 404 & $(67)$ & 260 & $(60)$ & \\
\hline Missing & 364 & & 93 & & 126 & & 145 & & \\
\hline cT stage & & & & & & & & & $<0.001$ \\
\hline $\mathrm{T} 1$ & 139 & (19) & 24 & (17) & 37 & (27) & 78 & $(56)$ & \\
\hline $\mathrm{T} 2$ & 347 & $(48)$ & 120 & $(35)$ & 133 & (38) & 94 & (27) & \\
\hline $\mathrm{T} 3$ & 150 & (21) & 57 & $(38)$ & 50 & (33) & 43 & $(29)$ & \\
\hline $\mathrm{T} 4 \mathrm{a}$ & 84 & (12) & 45 & $(54)$ & 24 & (29) & 15 & (18) & \\
\hline $\mathrm{Tx}$ & 1357 & & 526 & & 483 & & 348 & & \\
\hline $\mathrm{cN}$ stage & & & & & & & & & $<0.001$ \\
\hline No & 1326 & (77) & 440 & (33) & 483 & (36) & 403 & $(30)$ & \\
\hline $\mathrm{N}+$ & 387 & (23) & 181 & $(47)$ & 136 & $(35)$ & 70 & (18) & \\
\hline $\mathrm{Nx}$ & 364 & & 151 & & 108 & & 105 & & \\
\hline Year of diagnosis & & & & & & & & & $<0.001$ \\
\hline 2006-2008 & 934 & (45) & 426 & $(46)$ & 308 & (33) & 200 & (21) & \\
\hline 2009-2011 & 608 & (29) & 187 & (31) & 220 & $(36)$ & 201 & (33) & \\
\hline 2012-2014 & 535 & $(26)$ & 159 & $(30)$ & 199 & $(37)$ & 177 & $(33)$ & \\
\hline Referral status & & & & & & & & & $<0.001$ \\
\hline Diagnosis in treatment hospital & 1657 & $(86)$ & 674 & $(41)$ & 585 & $(35)$ & 398 & $(24)$ & \\
\hline Diagnosis in other hospital & 262 & (14) & 60 & $(23)$ & 81 & $(31)$ & 121 & $(46)$ & \\
\hline Missing & 158 & & 38 & & 61 & & 59 & & \\
\hline \multicolumn{10}{|c|}{ Treatment and histopathologic characteristics } \\
\hline Surgical type & & & & & & & & & 0.008 \\
\hline Distal gastrectomy & 1435 & (69) & 545 & $(38)$ & 501 & $(35)$ & 389 & $(27)$ & \\
\hline Total gastrectomy & 607 & (29) & 206 & (34) & 215 & $(35)$ & 186 & $(31)$ & \\
\hline Multiorgan surgery & 35 & (2) & 21 & $(60)$ & 11 & (31) & 3 & (9) & \\
\hline Surgical approach & & & & & & & & & 0.002 \\
\hline Open & 1908 & (94) & 728 & $(38)$ & 671 & $(35)$ & 509 & (27) & \\
\hline Laparoscopic & 129 & (6) & 33 & (26) & 45 & $(35)$ & 51 & $(40)$ & \\
\hline Missing & 40 & & 11 & & 11 & & 18 & & \\
\hline Radicality & & & & & & & & & 0.003 \\
\hline R0 & 1689 & (85) & 595 & $(35)$ & 599 & $(35)$ & 495 & (29) & \\
\hline R1-2 & 291 & (15) & 126 & (43) & 106 & $(36)$ & 59 & $(20)$ & \\
\hline $\mathrm{Rx}$ & 97 & & 51 & & 22 & & 24 & & \\
\hline pT stage & & & & & & & & & $<0.001$ \\
\hline $\mathrm{T} 1$ & 454 & $(22)$ & 89 & $(20)$ & 156 & (34) & 209 & $(46)$ & \\
\hline $\mathrm{T} 2$ & 321 & (16) & 104 & $(32)$ & 121 & (38) & 96 & $(30)$ & \\
\hline $\mathrm{T} 3$ & 747 & (36) & 321 & (43) & 259 & (35) & 167 & (22) & \\
\hline
\end{tabular}


TABLE 2 continued

\begin{tabular}{|c|c|c|c|c|c|c|c|c|c|}
\hline \multirow[t]{2}{*}{ Characteristic } & \multicolumn{2}{|c|}{ All $(N=2077)$} & \multicolumn{2}{|c|}{$<5$ weeks $(n=772)$} & \multicolumn{2}{|c|}{$5-8$ weeks $(n=727)$} & \multicolumn{2}{|c|}{$>8$ weeks $(n=578)$} & \multirow[t]{2}{*}{$p$} \\
\hline & $n$ & $(\%)$ & $n$ & $(\%)$ & $n$ & $(\%)$ & $n$ & $(\%)$ & \\
\hline $\mathrm{T} 4 \mathrm{a}$ & 489 & (24) & 234 & (48) & 166 & (34) & 89 & (18) & \\
\hline $\mathrm{T} 4 \mathrm{~b}$ & 55 & (3) & 23 & $(42)$ & 21 & $(38)$ & 11 & $(20)$ & \\
\hline $\mathrm{Tx}$ & 11 & & 1 & & 4 & & 6 & & $<0.001$ \\
\hline \multicolumn{10}{|l|}{$\mathrm{pN}$ stage } \\
\hline N0 & 995 & (48) & 291 & (29) & 346 & $(35)$ & 358 & (36) & \\
\hline N1 & 347 & $(17)$ & 137 & (39) & 127 & $(37)$ & 83 & $(24)$ & \\
\hline $\mathrm{N} 2$ & 336 & (16) & 146 & (43) & 121 & (36) & 69 & (21) & \\
\hline N3 & 390 & (19) & 193 & (49) & 130 & (33) & 67 & (17) & \\
\hline $\mathrm{Nx}$ & 9 & & 5 & & 3 & & 1 & & \\
\hline pM stage & & & & & & & & & 0.162 \\
\hline M0 & 2003 & (96) & 737 & (37) & 707 & (35) & 559 & (28) & \\
\hline M1 & 74 & (4) & 35 & $(47)$ & 20 & $(27)$ & 19 & $(26)$ & \\
\hline Curative intent & & & & & & & & & 0.035 \\
\hline Yes & 1946 & (94) & 713 & (37) & 687 & $(35)$ & 546 & (28) & \\
\hline No & 120 & (6) & 58 & $(48)$ & 36 & $(30)$ & 26 & $(22)$ & \\
\hline Missing & 11 & & 1 & & 4 & & 6 & & \\
\hline 90-day mortality & 240 & $(12)$ & 94 & (12) & 68 & (9) & 78 & (13) & 0.053 \\
\hline Adjuvant therapy & & & & & & & & & 0.043 \\
\hline No & 1993 & (96) & 730 & (37) & 704 & $(35)$ & 559 & (28) & \\
\hline Chemotherapy & 28 & (1) & 11 & (39) & 6 & $(21)$ & 11 & (39) & \\
\hline Radiotherapy & 1 & $(<1)$ & 1 & $(100)$ & 0 & $(0)$ & 0 & $(0)$ & \\
\hline Chemoradiation & 55 & (3) & 30 & (55) & 17 & (31) & 8 & (15) & \\
\hline
\end{tabular}

TABLE 3 Univariable and multivariable Cox proportional hazard analysis on influence of WT on risk of death in patients treated with neoadjuvant chemotherapy followed by gastrectomy or primary gastrectomy for cancer

\begin{tabular}{|c|c|c|c|c|}
\hline \multirow[t]{2}{*}{ Characteristic } & \multicolumn{2}{|l|}{ Univariable } & \multicolumn{2}{|l|}{ Multivariable $^{\mathrm{a}}$} \\
\hline & HR $(95 \% \mathrm{CI})$ & $p$ & HR $(95 \% \mathrm{CI})$ & $p$ \\
\hline \multicolumn{5}{|l|}{ Neoadjuvant treatment } \\
\hline $\mathrm{WT} \leq 5$ weeks & Ref & - & Ref & - \\
\hline WT 5-8 weeks & $0.79(0.67-0.94)$ & $0.008^{*}$ & $0.82(0.66-1.02)$ & 0.068 \\
\hline WT $>8$ weeks & $0.80(0.62-1.05)$ & 0.106 & $0.85(0.59-1.21)$ & 0.354 \\
\hline Additional week WT & $0.97(0.94-1.01)$ & 0.057 & $0.96(0.92-1.00)$ & 0.078 \\
\hline \multicolumn{5}{|l|}{ Surgery only } \\
\hline $\mathrm{WT} \leq 5$ weeks & Ref & - & Ref & - \\
\hline WT 5-8 weeks & $0.86(0.76-0.98)$ & $0.018 *$ & $0.92(0.81-1.05)$ & 0.200 \\
\hline WT $>8$ weeks & $0.75(0.65-0.86)$ & $<0.001 *$ & $0.95(0.79-1.08)$ & 0.314 \\
\hline Additional week WT & $0.97(0.96-0.99)$ & $<0.001 *$ & $0.99(0.98-1.01)$ & 0.264 \\
\hline
\end{tabular}

$C I$ confidence interval, $H R$ hazard ratio, $W T$ waiting time

* Statistically significant $(p<0.05)$

a Adjusted for baseline characteristics: age, gender, malignancy history, tumor differentiation, cT stage, cN stage, year of diagnosis, and referral status

WTs than patients diagnosed with pathologic early tumor stages. In the surgery group, this difference was already present at baseline, and therefore, it is assumed that patients with clinical advanced tumor stages may have had priority and may have been scheduled for surgery earlier. On the other hand, it can be hypothesized that some patients with clinical advanced tumor stages with a long WT may have developed disease progression as a result of 
this longer WT and eventually may have dropped out for surgery, and hence were not included in this study. Unfortunately, these dropouts could not be extracted from the NCR. Because both dropouts and palliative gastrectomies are due to disease progression, it is unlikely that there is a significant amount of dropouts with longer WTs. Because this study did not show a clinically relevant difference in WT between curative resections and palliative resections, we assume that dropouts were not likely to have affected the results significantly. In the neoadjuvant group, it remains unclear why patients with pathologic advanced tumor stages had shorter WTs. Early treatment due to worse tumor characteristics seems unlikely, as cTN stages were comparable between the WT groups, and moreover, no waiting list exists for the start of neoadjuvant chemotherapy in the Netherlands. Although median WTs in the palliative group did not exceed the median WTs in the curative group (both around 4 weeks), longer WTs might have caused dropouts, which resulted in patient selection. Furthermore, a discrepancy in clinical and pathologic tumor stages should be interpreted with caution for two reasons. First, imaging strategies currently used for clinical TN staging all have their specific limitations, and accurate prediction of pathologic TN stage is still not possible for an individual patient. ${ }^{24}$ Second, neoadjuvant chemotherapy downsizes the tumor and influences pathologic tumor stages.

In more recent years, WT to primary surgery increased, whereas WT to neoadjuvant therapy remained stable. We assume that this can be explained by the fact that most patients who underwent primary surgery after 2008 were not eligible for perioperative chemotherapy-for instance, as a result of poor condition. It is expected that in these patients, more time was needed to optimize them before the start of treatment. Moreover, patients treated with primary surgery needed more referral in the recent years (data not shown). Because additional time is needed for referral, the WT may have increased in this group.

In the Netherlands, WT is seen as an important quality indicator by several authorities. ${ }^{9,10}$ This study demonstrated that $57 \%$ of the patients who underwent neoadjuvant treatment, and $37 \%$ of the patients who underwent primary surgery, comply with this recommendation. For gastric cancer, this study demonstrated that there is no absolute need to strictly adhere to this recommendation for oncologic reasons. Factors such as patient delay and delay to diagnosis are probably more relevant for oncologic outcomes, as these time frames are relatively longer than the WT from diagnosis to treatment. ${ }^{23}$ Because WT does not impair oncologic outcomes within a clinically relevant time frame, it may be used to optimize these often malnourished patients before the start of the intensive treatment. ${ }^{25}$ In fact, optimizing patients could be an explanation for the fact that many patients were not treated within 5 weeks in our cohort. On the other hand, WT can have a negative (psychosocial) influence on patient factors such as quality of life. ${ }^{7}$ Efforts should therefore be made to keep the WT to a minimum. During WT, the results from this study can be used to reduce psychosocial distress by reassuring patients that longer WTs do not adversely affect oncologic outcomes.

This study has some limitations. First, although we adjusted for most of the generally accepted baseline characteristics in gastric cancer, other potential confounding factors may have been missed. For instance, data on patients' comorbidities, performance status, or nutritional status, symptoms of the tumor, and hospital factors were not available from the NCR database, but these data might have influenced the results. Second, although data from the NCR are being directly extracted from medical records within 9 months after diagnosis, the study was retrospective in nature, and possible confounders may have been missed. On the other hand, a randomized trial would not be ethical to evaluate the influence of WTs. Therefore, multivariable analysis as performed in this study will remain one of the best methods to investigate this topic. Nonetheless, this is the first nationwide cohort study investigating the effect of WT on survival in patients with gastric cancer in the West. The results of this study can be extrapolated to other countries in the West because treatment and outcomes of gastric cancer care are comparable and therefore can be used for the composition of (international) guidelines on gastric cancer treatment. ${ }^{26}$

In conclusion, this large population-based cohort study demonstrated that a longer WT between diagnosis and start of treatment with curative intent for gastric cancer is not associated with worse OS. Although efforts should be made to keep WT to a minimum for patients' quality of life, these results could help establish new cancer-specific guidelines and reassure patients with gastric cancer.

ACKNOWLEDGMENT The authors thank the NCR (IKNL) for collecting and supplying the data for this study.

DISCLOSURE The authors declare no conflict of interest.

OPEN ACCESS This article is distributed under the terms of the Creative Commons Attribution 4.0 International License (http:// creativecommons.org/licenses/by/4.0/), which permits unrestricted use, distribution, and reproduction in any medium, provided you give appropriate credit to the original author(s) and the source, provide a link to the Creative Commons license, and indicate if changes were made.

\section{REFERENCES}

1. Ferlay J, Soerjomataram I, Dikshit R, et al. Cancer incidence and mortality worldwide: sources, methods and major patterns in GLOBOCAN 2012. Int J Cancer. 2015;136:E359-86. 
2. Vereniging Integrale Kankercentra. Diagnostiek, behandeling en follow-up van het maagcarcinoom. 2009. http://www.oncoline.nl/ uploaded/docs/Maagcarcinoom/Richtlijn\%20maagcarcinoom.pdf.

3. Cunningham D, Allum WH, Stenning SP, et al. Perioperative chemotherapy versus surgery alone for resectable gastroesophageal cancer. N Engl J Med. 2006;355:11-20.

4. Hartgrink HH, van de Velde CJ, Putter H, et al. Extended lymph node dissection for gastric cancer: who may benefit? Final results of the randomized Dutch gastric cancer group trial. J Clin Oncol. 2004;22:2069-77.

5. Yoo CH, Noh SH, Shin DW, Choi SH, Min JS. Recurrence following curative resection for gastric carcinoma. $\mathrm{Br} J$ Surg. 2000;87:236-42.

6. DUCA Jaarrapportage, 2014. Available at: http://www. clinicalaudit.nl/jaarrapportage/2014/duca.html.

7. Visser MR, van Lanschot JJ, van der Velden J, Kloek JJ, Gouma DJ, Sprangers MA. Quality of life in newly diagnosed cancer patients waiting for surgery is seriously impaired. J Surg Oncol. 2006;93:571-7.

8. Neal RD, Tharmanathan P, France B, et al. Is increased time to diagnosis and treatment in symptomatic cancer associated with poorer outcomes? Systematic review. Br J Cancer. 2015;112 (suppl 1):S92-107.

9. Advies inzake wachttijdnormen in de kankerzorg. http://www. oncoline.nl/uploaded/docs/Draaiboek/Normatieve $\% 20$ wachttijden.pdf.

10. Normeringsrapport SONCOS. February 6, 2015. http://www. soncos.org/.

11. Yun YH, Kim YA, Min YH, et al. The influence of hospital volume and surgical treatment delay on long-term survival after cancer surgery. Ann Oncol. 2012;23:2731-7.

12. Griffin SM. Gastric cancer in the East: same disease, different patient. Br J Surg. 2005;92:1055-6.

13. Japanese Gastric Cancer Association. Japanese gastric cancer treatment guidelines 2010 (ver. 3). Gastric Cancer. 2011;14:113-23.

14. Japanese Gastric Cancer Association. Japanese classification of gastric carcinoma: 3rd English edition. Gastric Cancer. 2011;14:101-12.

15. Visser E, Leeftink AG, van Rossum PS, Siesling S, van Hillegersberg R, Ruurda JP. Waiting time from diagnosis to treatment has no impact on survival in patients with esophageal cancer. Ann Surg Oncol. 2016;23:2679-89.

16. Grotenhuis BA, van Hagen P, Wijnhoven BP, Spaander MC, Tilanus HW, van Lanschot JJ. Delay in diagnostic workup and treatment of esophageal cancer. J Gastrointest Surg. 2010;14: 476-83.

17. McLaughlin JM, Anderson RT, Ferketich AK, Seiber EE, Balkrishnan R, Paskett ED. Effect on survival of longer intervals between confirmed diagnosis and treatment initiation among lowincome women with breast cancer. J Clin Oncol. 2012;30: 4493-500.

18. Elit LM, O'Leary EM, Pond GR, Seow HY. Impact of wait times on survival for women with uterine cancer. J Clin Oncol. 2014;32:27-33.

19. van Harten MC, Hoebers FJ, Kross KW, van Werkhoven ED, van den Brekel MW, van Dijk BA. Determinants of treatment waiting times for head and neck cancer in the Netherlands and their relation to survival. Oral Oncol. 2015;51:272-8.

20. Eshuis WJ, van der Gaag NA, Rauws EA, et al. Therapeutic delay and survival after surgery for cancer of the pancreatic head with or without preoperative biliary drainage. Ann Surg. 2010;252:840-9.

21. Murchie P, Raja EA, Brewster DH, et al. Time from first presentation in primary care to treatment of symptomatic colorectal cancer: effect on disease stage and survival. $\mathrm{Br} J$ Cancer. 2014;111:461-9.

22. Ramos M, Esteva M, Cabeza E, Campillo C, Llobera J, Aguilo A. Relationship of diagnostic and therapeutic delay with survival in colorectal cancer: a review. Eur J Cancer. 2007;43:2467-78.

23. Witzig R, Schonberger B, Fink U, et al. Delays in diagnosis and therapy of gastric cancer and esophageal adenocarcinoma. Endoscopy. 2006;38:1122-6.

24. Seevaratnam R, Cardoso R, McGregor C, et al. How useful is preoperative imaging for tumor, node, metastasis (TNM) staging of gastric cancer? A meta-analysis. Gastric Cancer. 2012;15(suppl 1): S3-18.

25. Correia MI, Waitzberg DL. The impact of malnutrition on morbidity, mortality, length of hospital stay and costs evaluated through a multivariate model analysis. Clin Nutr. 2003;22:235-9.

26. Dikken JL, van Sandick JW, Allum WH, et al. Differences in outcomes of oesophageal and gastric cancer surgery across Europe. Br J Surg. 2013;100:83-94. 